\title{
MECHANISM OF HOUSE FLY RESISTANCE: I- Toxicity of Cypermethrin, Imidacoloprid and Spinosad to Larvae and Adults of the Laboratory Strain
}

\section{Doaa El-Sherif ${ }^{1}$, Ahmed Etman ${ }^{1}$, Makram Sayed ${ }^{1}$ and Zaki El-} Fiky $^{2}$

1. Plant Protection Dept, Faculty of Agric. Fayoum Univ.

2. Genetic Dept. Faculty of Agric. Fayoum Univ.

\begin{abstract}
The house fly, Musca domestica L., is a vector for more than 100 human and animal diseases and has the ability to develope resistance to different insecticides. This study evaluated toxicity of Cypermethrin, Imidacloprid and Spinosad, in addition to, their mixtures under laboratory conditions against larvae and adults of $M$. domestica for laboratory strain. The $\mathrm{LC}_{50} \mathrm{~S}$ of the three tested insecticides were $579.30,415.46$ and $16.32 \mathrm{ppm}$, respectively, against larvae $48 \mathrm{~h}$ post treatment. The toxic effect of these insecticides against $M$. domestica adults was assessed $24 \mathrm{~h}$ post treatment. The $\mathrm{LC}_{50} \mathrm{~S}$ of Cypermethrin, Imidacloprid and Spinosad were 208.75, 238.3 and $86.05 \mathrm{ppm}$, respectively, against the laboratory strain. This study also showed efficacy of the binary mixtures of these insecticides, where the mixture of Cypermethrin+Imidacloprid and Cypermethrin+Spinosad showed potentiation at ratios 1:1, 1:2 and 2:1. On other hand, the mixture of Imidaclporid+Spinosad showed an additive effect at all mixing ratios.
\end{abstract}

\section{INTRODUCTION}

The house fly, Musca domestica (Linnaeus), is a major domestic, medical and veterinary pest that transmit more than 100 to human and animal diseases, including bacterial infections such as salmonellosis, anthrax ophthalmic, shigellosis, typhoid fever, tuberculosis, cholera and infantile diarrhea; protozoan infections such as amebic dysentery; helminthic infections such as pinworms, hook worms and tapeworms; and both viral and rickettsial infections ( $\mathrm{Li}$, et al., 2013). Also, house fly plays a role as a vector for Yersinia pseudotuberculosis, which results in high avian mortality on poultry farms. So that, the caused infestations reduced feed conversion Fayoum J. Agric. Res. \& Dev., Vol. 33, No.2, July, 2019 
Doaa El-Sherif ${ }^{1}$, et, al.,

efficiency, and increased stress levels for young or adult animals, leading up to $\$ 200$ million in annual production losses (Rinkevich, et al., 2013).

This study discusses the toxicological impact of Cypermethrin, Imidacloprid and Spinosad against the laboratory strain of house fly. In addition to, the efficiency of the binary mixture of these insecticides in controlling house flies.

\section{MATERIALS AND METHODS}

\section{Insecticides}

Three insecticides in their formulations form Cypermethrin (Cymbush $^{\circledR} 10 \%$ EC), Imidaclopride (Imidazed ${ }^{\circledR} 20 \%$ SC) and Spinosad (Tracer ${ }^{\circledR} 24 \%$ SC) were used to calculate their $\mathrm{LC}_{50}$ values.

\section{Rearing media.}

Larval medium: This medium was prepared freshly according to the method described by Singh and Jerram (1976) with a slight modification. The bran was used instead of the agar. The medium consisted of $40 \mathrm{~g}$ milk powder, $150 \mathrm{~g}$ wheat middling (bran), $20 \mathrm{~g}$ yeast powder, $0.3 \mathrm{~g}$ methyl $\beta$ hydroxyl benzoate, and $0.1 \mathrm{~g}$ streptomycin sulphate. The contents were mixed and wetted with water.

Adult medium: This medium was prepared according to Singh and Jerram, (1976) method with a slight modification. The present medium does not contain egg yolk powder and cholesterol. Two media were used: the first was paper rolls saturated with $2.5 \%$ sugar solution; and the second was a solid nutrient mixture consisted of $9 \mathrm{~g}$ sugar, $9 \mathrm{~g}$ milk powder and $2 \mathrm{~g}$ yeast powder.

Rearing cages: Wooden cages with the dimensions of $72 \mathrm{~cm}$ height, $60 \mathrm{~cm}$ length, and $54 \mathrm{~cm}$ width. The front side of each cage has a circular hole which closed with a tube of muslin to provide the adults with the diet. Two sides of the cage were covered with muslin cloth to allow aeration for the cage, and the fourth side was made of glass to permit a follow up of the rearing process.

\section{Rearing of Musca domestica $\mathbf{L}$.}

A strain of $M$. domestica larvae was collected from the accumulation of garbage places of Fayoum Governorate. This strain was colonized in the previously described cages and provided with the

Fayoum J. Agric. Res. \& Dev., Vol. 33, No.2, July, 2019 
MECHANISM OF HOUSE FLY RESISTANCE: I- Toxicity..... 83 adults' medium. Twenty five grams of larval medium was placed in a small plastic tray as an oviposition site and placed with adults in the rearing cage. The medium containing laid eggs was transferred to an incubator under a constant temperature of $30 \pm 2{ }^{\circ} \mathrm{C}$. until pupation, the collected pupae were transferred to cages provided with adult medium at room temperature.

The house fly was reared in the laboratory for 30 generations in the insects rearing room at the Plant Protection Department, Faculty of Agriculture, Fayoum University, without any exposure to insecticides. Treatment of larvae

The method of larvae treatment was described by Siriwattanarungsee, et al., (2008). One hundred grams of larvae medium was used for each insecticide concentration and divided into four portions (25g each) in a small plastic tray. Twenty five of the second instar larvae were transferred to the poisonous bait tray and kept in an incubator at a constant temperature of $30 \pm 2{ }^{\circ} \mathrm{C}$ with a relative humidity of $50-60 \%$. The mortality percentage calculated after $48 \mathrm{~h}$ treatment.

\section{Treatment of adults:}

The base of the bait consisted of a mixture of black honey and dry yeast powders at the ratio of 1:2, mixed to form a paste. Different concentrations of each tested insecticide were prepared and added to the paste to get poison bait. Each concentration was divided into four replicates and about one gram of the toxic bait was spread over slices of aluminum foil. Twenty five adults were introduced into each plastic jar, then one prepared aluminum foil slice was suspended in the jar opening and fixed by the jar cover. Small holes were made in the cover to allow ventilation. The jars were kept in an incubator at a constant temperature of $28^{\circ} \mathrm{C} \pm 2$ and a relative humidity of $50-60 \% \pm 5$ and the mortality rate was recorded at $24 \mathrm{~h}$ post treatment

\section{Effect of binary mixtures}

The calculated values of $\mathrm{LC}_{25}$ of Cypermethrin, Imidaclprid and Spinosad were used to make the binary insecticide combination at the

Fayoum J. Agric. Res. \& Dev., Vol. 33, No.2, July, 2019 
Doaa El-Sherif ${ }^{1}$, et, al.,

ratios of 1:1, 1:2 and 2:1. The prepared mixture was added to the adult's media to get toxic bait, which introduced to the house fly adults. Percent mortality was recorded at $24 \mathrm{~h}$ post treatment and the cotoxicity factor was estimated according to the equation represented by (Mansour, et al., 1966 and 2010), as follows,

Observed mortality - Expected mortality

Co-Toxicity factor (C.F) $=$ 100

Expected mortality

A positive value from +20 or more indicates potentiation, a negative factor of -20 or less indicates antagonism, and the intermediate values of $>-20$ to $<+20$ indicates an additive effect

Statistical analysis:

The mortality data were corrected by the Abbott formula (Abbott, 1925), and toxicity line was plotted according to Finney analysis (Finney, 1971). The software program (Micro Origin) was used for the statistical analysis of the data and plotting the histograms.

\section{RESULTS AND DISCUSSION}

1- $\quad$ Toxicity against $M$. domestica larvae.

Spinosad exhibited the most toxic effect on the laboratory strain, while Cypermethrin was the least toxic depending on the value of the $\mathrm{LC}_{50}$ and $\mathrm{LC}_{90}$ (Table ' and Fig. 1). The treatments could be arranged in a descending order according to their toxic effect as follows: Spinosad, Imidacloprid and Cypermethrin, with $\mathrm{LC}_{50}$ 's of $16.32,415.46$ and $579.30 \mathrm{ppm}$, respectively. This finding agrees with Kristensen and Jespersen, (2004) and Abo-El-Maged, (2014), who reported that, Spinosad was highly toxic to the larvae of house fly.

Fayoum J. Agric. Res. \& Dev., Vol. 33, No.2, July, 2019 
MECHANISM OF HOUSE FLY RESISTANCE: I- Toxicity..... 85 Table (1). The $\mathrm{LC}_{50}, \mathrm{LC}_{90}(\mathrm{ppm})$ and slope values at $48 \mathrm{~h}$ post treatment of Cypermethrin, Imidacloprid and Spinosad against the laboratory strain of $M$. domestica larvae.

\begin{tabular}{|c|c|c|c|c|c|c|c|}
\hline \multirow{2}{*}{ Insecticides } & \multirow{2}{*}{$\mathrm{LC}_{50}$} & \multicolumn{2}{|c|}{ Confidence Level } & \multirow{2}{*}{$\mathrm{LC}_{90}$} & \multicolumn{2}{c|}{ Confidence Level } & \multirow{2}{*}{ Slope $\pm \mathrm{SE}^{*}$} \\
\cline { 3 - 4 } & & Lower & Upper & & Lower & Upper & \\
\hline Cypermethrin & 579.30 & 471.06 & 697.65 & 3628.27 & 2497.67 & 6573.93 & $1.61 \pm 0.2$ \\
\hline Imidacloprid & 415.46 & 351.39 & 481.09 & 1748.82 & 1326.48 & 2681.51 & $2.05 \pm 0.25$ \\
\hline Spinosad & 16.32 & 14.09 & 18.8 & 69.09 & 55.05 & 93.06 & $2.05 \pm 0.17$ \\
\hline
\end{tabular}

$* \mathrm{SE}=$ Standard Error

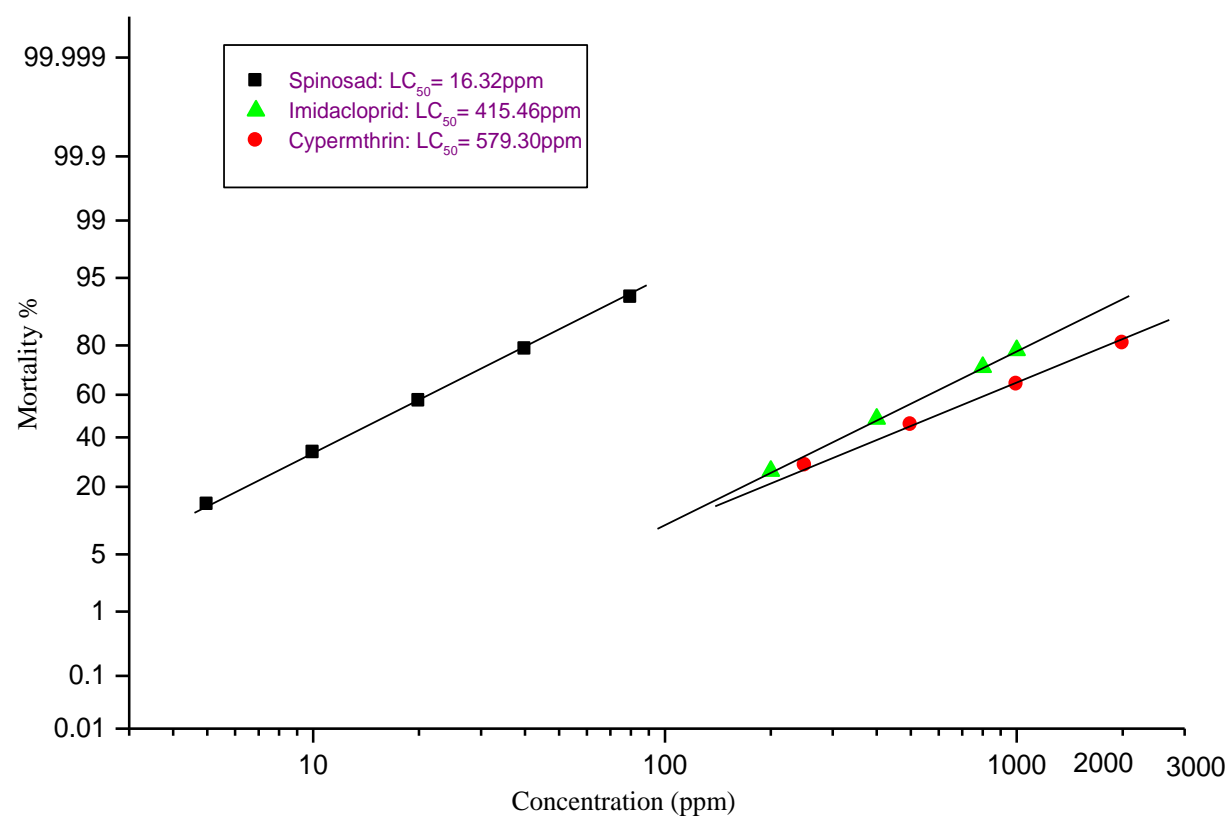

Fig (1) Toxicity Lines of the tested insecticides against the laboratory strain of M.domestica larvae

Fayoum J. Agric. Res. \& Dev., Vol. 33, No.2, July, 2019 


\section{2- Toxicity against $M$. domestica adults.}

Table (2) and Fig. (2) show the toxicity of tested insecticides at $24 \mathrm{~h}$ post treatment against laboratory of $M$. domestica adults. Spinosad was the most toxic insecticide with $\mathrm{LC}_{50}$ value was $86.05 \mathrm{ppm}$. The least toxic insecticide to the laboratory strain was Imidacloprid with $\mathrm{LC}_{50}$ of $238.3 \mathrm{ppm}$.

Deacutis, et al.,(2006) studied the efficacy of Spinosad assessed by three bioassay methods, topical application, feeding and residual exposure on $M$. domestica, the $\mathrm{LD}_{50}$ or $\mathrm{LC}_{50}$ was $0.054 \mu \mathrm{g} / \mathrm{fly}, 2.85 \mu \mathrm{g} / \mathrm{g}$ and $0.064 \mu \mathrm{g} / \mathrm{cm}^{2}$, respectively. In addition, Kaufman, et al., (2006 they showed susceptibility of Imidacloprid to laboratory strain and field population of $M$. domestica, that collected from the United States, their $\mathrm{LC}_{50}$ were $30 \mathrm{ppm}$ for each other. Further more, these results agreed with Asid, et al., (2015), who reported that Cypermethrin against laboratory and field strains, gave $\mathrm{LD}_{50} 0.0223$ and $0.0645 \mathrm{ppm}$, respectively.

Table (2). The $\mathrm{LC}_{50}, \mathrm{LC}_{90}(\mathrm{ppm})$ and slope values at $24 \mathrm{~h}$ post treatment of Cypermethrin, Imidacloprid and Spinosad against laboratory strain of $M$. domestica adult.

\begin{tabular}{|c|c|c|c|c|c|c|c|}
\hline \multirow{2}{*}{ Insecticides } & \multirow{2}{*}{ LC $_{50}$} & \multicolumn{2}{|c|}{$\begin{array}{c}\text { Confidence } \\
\text { Level }\end{array}$} & \multirow{2}{*}{ LC $_{90}$} & \multirow{2}{*}{ Confidence Level } & \multirow{2}{*}{ Slope \pm SE* $^{*}$} \\
\cline { 3 - 4 } \cline { 6 - 7 } & & Lower & Upper & & Lower & Upper & \\
\hline Cypermethrin & 208.75 & 176.22 & 253.46 & 957.65 & 668.89 & 1660.23 & $1.94 \pm 0.23$ \\
\hline Imidacloprid & 238.3 & 204.93 & 282.03 & 809.65 & 590.78 & 1373 & $2.41 \pm 0.33$ \\
\hline Spinosad & 86.05 & 72.39 & 100.19 & 302.93 & 229.1 & 481.99 & $2.34 \pm 0.33$ \\
\hline
\end{tabular}

$* \mathrm{SE}=$ Standard Error

Fayoum J. Agric. Res. \& Dev., Vol. 33, No.2, July, 2019 
MECHANISM OF HOUSE FLY RESISTANCE: I- Toxicity ..... 87

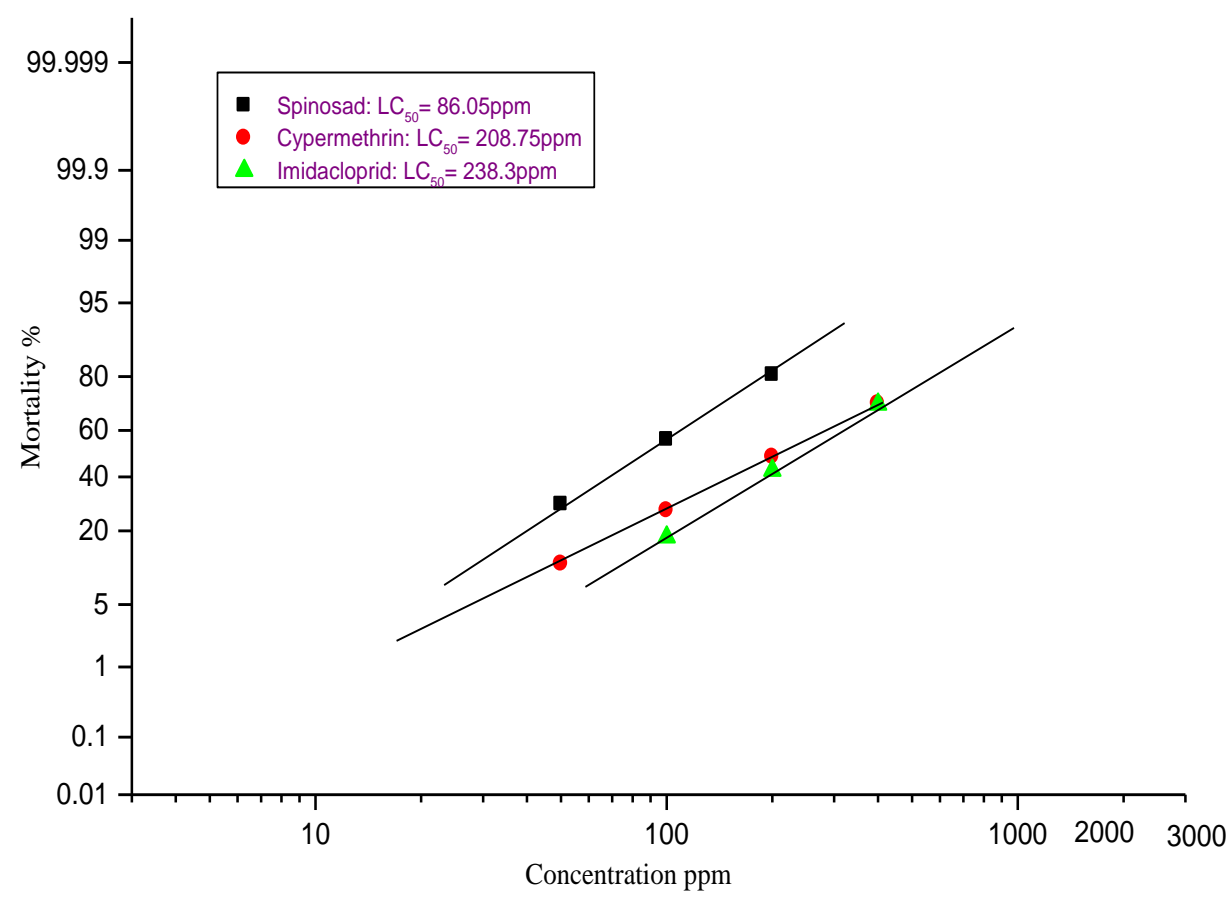

Fig (2) Toxicity Lines of the tested insecticides against the laboratory strain of M.domestica adults

\section{Effect of binary mixtures}

The interaction effects among the tested insecticides depended on the type of insecticide used, ratios and strains. The $\mathrm{LC}_{25}$ of Cypermethrin, Imidacloprid and Spinosad were used to make the binary insecticide combinations, where calculated as 89.5, 125 and $41 \mathrm{ppm}$, respectively against the laboratory strain.

Data in (Table 3) show the effect of the insecticide mixtures against the laboratory strain. The mixture of Cypermethrin+ Imidacloprid showed potentiation at the ratios of $1: 1,1: 2$ and 2:1 against adults $M$. domestica and it exhibted high potentiation in the

Fayoum J. Agric. Res. \& Dev., Vol. 33, No.2, July, 2019 
Doaa El-Sherif ${ }^{1}$, et, al.,

laboratory strain at the ratio of 1:1, where the co-toxicity factor was 46 . This could be because of different modes of action they poses, or because the binding of monooxygenase enzymes with Imidacloprid insecticide would prevent or delay the degradation, and enhance the toxicity of Cypermethrin by competitive substrate inhibition mechanism. As is the case in some organophosphate insecticides which bind to the active site associated with esterase enzymes responsible for detoxification of pyrethroid-based insecticides (Cloyd, 2011 and Ahmad, 2009).

The mixture of Cypermethrin with Spinosad gave the highest co-toxicity factors at the ratio of $1: 1$, recording 66 . In addition, it gave a potentiation in 1:2 and 2:1 ratios, where co-toxicity factors were 24 and 21.3, respectively. This is useful in the control of $M$. domestica. The toxicity of pyrethroids could be enhanced by the addition of new insecticides like Emamectin benzoate, Fipronil and Spinosad. According to this, one toxicant in the mixture interferes with the metabolic detoxification of the other toxicant, Khan, et al., (2013) who demonstrated that the mixture of Cypermethrin+Emamectin gave a synergistic action. These results conversely agree with Abbas, et al., (2015) who revealed that combination indices for LambdaCyhalothrin+Emamectin benzoate and Lambda-Cyhalothrin+ Spinosad mixtures were significantly less than 1 , demonstrating an antagonistic effect. Thus, Vayias, et al., (2010), revealed that the combination of Spinosad with Deltamethrin did not appear to be compatible with $S$. oryzae.

The potentiation effect was also demonstrated in the case of the combination between pyrethroids and organophosphates by (Zahidul and Khalequzzaman, 2002 and Asid, et al., 2017). On the other hand, the mixture of Imidaclporid+Spinosad showed an additive effect at all mixing ratios. Also, the mixture containing Fipronil and Acetamiprid had an additive effect on $M$. domestica (Levchenko, et al., 2018).

Fayoum J. Agric. Res. \& Dev., Vol. 33, No.2, July, 2019 
MECHANISM OF HOUSE FLY RESISTANCE: I- Toxicity..... 89 Table (3) Effect of binary mixtures of Cypermethrin, Imidacloprid and Spinosad at the $\mathrm{LC}_{25}$ level against $M$. domestica.

\begin{tabular}{|c|c|c|c|}
\hline \multirow{2}{*}{$\begin{array}{c}\text { Mixing } \\
\text { ratio }\end{array}$} & \multicolumn{3}{|c|}{ Co-toxicity factor } \\
\cline { 2 - 4 } & Cypermethrin+Imidacloprid & Cypermethrin+Spinosad & Imidacloprid+Spinosad \\
\hline $1: 1$ & $46 \mathrm{P}^{*}$ & $66 \mathrm{P}$ & $10 \mathrm{Ad}^{* *}$ \\
\hline $1: 2$ & $29 \mathrm{p}$ & $24 \mathrm{P}$ & $4 \mathrm{Ad}$ \\
\hline $2: 1$ & $24 \mathrm{P}$ & $21.3 \mathrm{p}$ & $2.7 \mathrm{Ad}$ \\
\hline
\end{tabular}

*P. Potentiation effect

**Ad. Additive effect

\section{REFERENCES}

Abbas, N.; N. Crickmore and S. A. Shad (2015). Efficacy of insecticide mixtures against a resistant strain of house fly (Diptera: Muscidae) collected from a poultry farm. J. Trop Insect Sci., 35: 48-53.

Abbot, W. S (1925). The effectiveness of an insecticide. J. Econ. Entomol., 18: 265- 267.

Abo-El-Maged, T. M (2014). Field and laboratory evaluation of spinosad and spinetoram against house fly, Musca domestica L. (Diptera: Muscidae). J. Plant Prot., 5: 1073 $-1080$.

Ahmad, M. (2009). Observed potentiation between pyrethroid and organophosphate insecticides for the management of Spodoptera litura (Lepidoptera: Noctuidae). Crop Protect., 28: 264-268.

Asid, A. N.; K. M. Al-Ghamd; J. A. Mahyoub; M. I. Nassar; A. Mangoud.; A. R. Al- Najada and B. Z. Alfarhan (2015). Topical application of some pyrethroids against

Fayoum J. Agric. Res. \& Dev., Vol. 33, No.2, July, 2019 
Doaa El-Sherif ${ }^{1}$, et, al.,

the housefly, Musca domestica L. J. Life Sci., 12: 148153.

Asid, A. N.; K.M. Al-Ghamdi.; A. A. H Mangoud.; K. Al Asiry.; N. A Alkenani and Y. Anwar (2017). Synergistic effect of insecticides on the larvae and adults of housefly, Musca domestica L. J. Entomol Zool., 5: 899-905.

Cloyd, R. A (2011). Pesticide Mixtures, Pesticides - Formulations, Effects, book. ISBN: 978-953-307-532-7.

Deacutis, J. M.; C. A. Leichter, A. C. Gerry.; D. A. Rutz.; W. D. Watson.; C. J. Geden and J. G. Scott (2006). Susceptibility of field collected house flies to Spinosad before and after a season of Use. J. Agric. Urban Entomol., 23 (2): 105-110.

Finney, D. J (1971). Probit analysis. Cambridge Univ. Press, Cambridge.

Kaufman, P. E.; A. C. Gerry.; D. A. Rutze and J. G. Scott (2006). Monitoring susceptibality of house flies (Musca domestica) in the United States to Imidacloprid. J. Agric. Urban Entomol., 23 (4): 195 - 200.

Khan, H.A.A.; W. Akram.; S.A Shad and J. Lee (2013). Insecticide mixtures could enhance the toxicity of insecticides in a resistant dairy population of Musca domestica L. Plos one, 13(4): 1-8.

Kristensen, M. and J. B. Jespersen (2004). Susceptibility of Spinosad in Musca domestica (Diptera: Muscidae) field populations. J. Econ. Entomol., 97(3): 1042-1048.

Levchenko, M.A.; E. A. Silivanova.; R.K. Bikinyaeva and G. F. Balabanova (2018). Efficacy of Acetamiprid and Fipronil fly baits against the housefly (Musca domestica L.) under laboratory conditions. Veterinary World, 11: 953-958.

Li, M.; W. R Reid; L. Zhang; J. G Scott; X. Gao; M. Kristensen and N. Liu (2013). A whole transcriptomal linkage analysis of gene co-regulation in insecticide resistant house flies, Musca domestica. BMC Genomics, 14: 14712164.

Fayoum J. Agric. Res. \& Dev., Vol. 33, No.2, July, 2019 
MECHANISM OF HOUSE FLY RESISTANCE: I- Toxicity..... 91 Mansour, N. A.; M. E. El-Defrawi.; A. Toppozada and M. Zied (1966). Toxicological studies on the Egyptian cotton leaf worm Prodenia litura, potentiation and antagonism of organophosphorus and carbamate insecticides. J. Econ. Entomol., 59(2): 307-311.

Mansour, S. A.; R. F.A. Bakr.; L. S. A. Hamouda and R. I. Mohamed (2010). Toxic and Synergistic Properties of Several Botanical Extracts against Larval and Adult Stages of the Mosquito, Anopheles. pharoensis Bio. pestic. Int, 6: 129-145.

Rinkevich, F. D.; C. A. Leichter; T. A. Lazo; M. C. Hardstone and J. G. Scott (2013). Variable fitness costs for pyrethroid resistance alleles in the house fly, Musca domestica, in the absence of insecticide pressure. Pestic. Biochem. Physiol., 105: $161-168$

Singh, P. and E.M. Jerram (1976). Rearing house fly larvae in polythen bags. J. Zool., 3: 37 -58.

Siriwattanarungsee, S.; K. L. Sukontason.; J. K. Olson.; O. Chailapakul and K. Sukontason (2008). Efficacy of neem extract against the blowfly and house fly. Parasitol. Res., 103: 535-544.

Vayias, B.J.; N.G. Kavallieratos.; C.G. Athanassiou and G. Tatsi (2010). Insecticidal action of the combined use of Spinosad and Deltamethrin against three stored product pests in two stored hard-wheat varieties. Crop Protect., 425: 919-922.

Zahidul, I. $M$ and M. Khalequzzaman (2002). Potentiation of Malathion by other insecticides against adult housefly. Pakistan J. Biol. Sci., 5: 299- 302.

Fayoum J. Agric. Res. \& Dev., Vol. 33, No.2, July, 2019 
ميكانيكية مقاومة الذبابة المنزلية: اــ التأثير السام للسيبرمثرين، الايميداكلوبريد

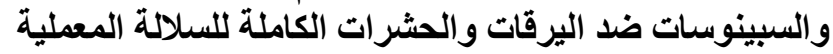

دعاء الثريف، ا.د/ احمد عتمان، ا.د/ مكرم سيد وأ.د/ زكى الفقى

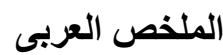

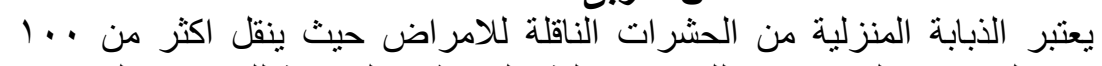

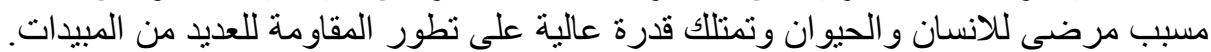

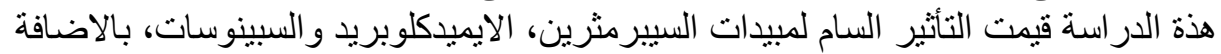

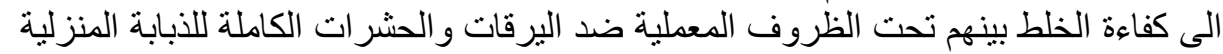

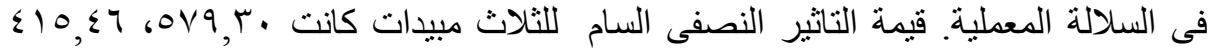

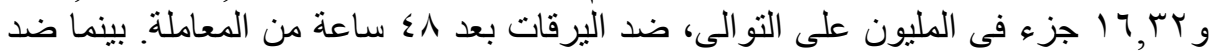

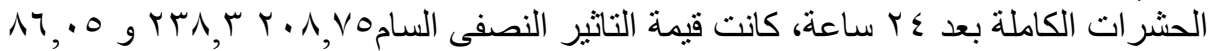

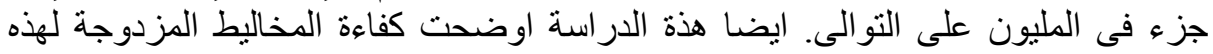

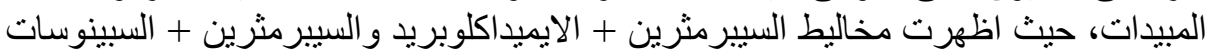

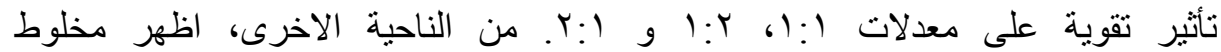
الايميداكلوبريد + السبينوساد تأثير اضافة على كل المعلى المعلات.

Fayoum J. Agric. Res. \& Dev., Vol. 33, No.2, July, 2019 